\title{
Interaction of Building Frame with Pile Foundation
}

\author{
Varnika Srivastava, H. S. Chore, P. A. Dode \\ Department of Civil Engineering, Datta Meghe College of Engineering, Airoli, Navi Mumbai, India \\ Email:vrnkasrivastava@gmail.com, chorehs@gmail.com,padode@rediffmail.com
}

Received 20 February 2016; accepted 27 March 2016; published 30 March 2016

Copyright $@ 2016$ by authors and Scientific Research Publishing Inc.

This work is licensed under the Creative Commons Attribution International License (CC BY). http://creativecommons.org/licenses/by/4.0/

(c) (;) Open Access

\section{Abstract}

The study deals with physical modeling of a typical building frame resting on a pile group embedded in cohesive soil mass using complete three-dimensional finite element analysis. The elements of the superstructure frame and that of the pile foundation are discretized using twenty node isoparametric continuum elements. The interface between the pile and pile cap is idealized using sixteen node isoparametric surface elements. The more improved finite element mesh is used for modeling soil element as compared to the one used in the study reported in the literature. The soil elements are discretized using eight node, nine node and twelve node continuum elements. Both the elements of superstructure and substructure (i.e., foundation) including soil are assumed to remain in elastic state at all the time. The interaction analysis is carried out using sub-structure approach to attempt a parametric study. The effect of the parameter such as spacing between the piles in a group and diameter of pile is evaluated on the response of superstructure. The response includes the displacement at the top of the frame. The effect of the soil-structure interaction is observed to be significant for the type of foundation and soil considered in the present study.

\section{Keywords}

Soil-Structure Interaction, Pile Groups, Pile Spacing, Pile Diameter, Top Displacement, Bending Moment

\section{Introduction}

The framed structures are normally analyzed with their bases considered to be either completely rigid or hinged. However, the foundation resting on deformable soils also undergoes deformation depending on the relative rigidities of the foundation, superstructure and soil. Interactive analysis is, therefore, necessary for the accurate assessment of the response of the superstructure. Numerous interactive analyses [1]-[5] have been reported in 
many studies in the 1960's and 1970's and few in recent studies [6]-[12]. While most of the above mentioned studies dealt with the quantification of the effect of interaction of frames with isolated footings or combined footings or raft foundation in the context of supporting sub-soil either analytically or experimentally; only the study by Buragohain et al. [5] was found to deal with the interaction analysis of frames on piles until recent past.

The work presented by Buragohain et al. [5] was carried out using the stiffness matrix method and moreover, it was based on the simplified assumptions and relatively less realistic approach. Pointing out the lacunae in the interaction analysis of a framed structure resting on pile foundation presented by Buragohain et al. [5], Chore and co-authors [13]-[17] reported the methodology for the interaction analysis of a single storeyed building frame embedded in clayey soil on the rational approach and realistic assumptions. Although most of the analyses used sub-structure method (uncoupled approach), few of them used coupled approach where the structure and foundation were considered to be a single compatible unit. However, the investigations underscored that the sub-structure approach is preferred in such interaction analysis owing to simplicity in the method, less memory requirement on part of the computational resources and not much variation in the results obtained using substructure method and coupled approach. Recently along similar lines, Reddy and Rao [18] reported an experimental work on a model building frame supported by a pile group and compared the results analytically using finite element analysis. Even numerous studies [19]-[24] have been reported most recently. However, these studies were confined to the interaction analysis of frames or allied structure supported by isolated footings or raft foundation.

In the meantime, much work is available in the literature on axially loaded as well as laterally loaded single pile and pile groups. The approaches available for the analysis of axially loaded pile foundations include the elastic continuum method [25] [26] and load transfer method [27]-[29], while those for analyzing the laterally loaded pile foundations include the elastic continuum approach [30]-[32] and modulus of subgrade reaction approach [33]-[36]. With the advent of computers in the early seventies, more versatile finite element method [37]-[44] has become popular for analyzing the problem of pile foundations in the context of linear and non-linear analysis.

On the backdrop of the considerable work of the interaction analyses of space frame-pile foundation-soil system reported in the recent past, the interaction analysis of a single storied frame resting on pile foundation is reported in this investigation. However, more refined 3-D F.E. mesh is used for pile foundation, wherein soil elements are discredited using three different elements - eight node, nine node and twelve node continuum elements, as compared to the mesh employed in the similar study [8] wherein the soil mass was discredited using twenty node continuum elements. Further, the effect of spacing between the piles, pile diameter along with the arrangement of piles (such as series and parallel) with respect to lateral loads acting on the frame was considered.

Further, the piles that were modeled were square for simplicity in modeling. However, while considering its effect, they were treated as the circular piles of the diameter equivalent to the size of the square piles. The flexible pile cap along with its stiffness is considered and the stiffness matrix for the sub-structure is derived by considering the effect of all the piles in a group. The behavior of elements of the superstructure and sub-structure including soil is considered to be linearly elastic. The total stress analysis is carried out and immediate behavior of the soil is considered.

\section{Hypothesis in Mathematical Modeling}

The interaction analysis is carried out using the finite element method. A typical frame is analyzed separately considering the fixed column bases. Later, the pile foundations are worked out independently to get the equivalent stiffness of the foundation head. Further, they are used in the interaction analysis to evaluate the effect of SSI on the response of the frame.

A three dimensional geometric model of the superstructure frame-pile foundation-soil system. The elements of the superstructure (beam, column and slab) and that of pile foundation (pile and pile cap) are discretized into 20 node iso-parametric continuum elements. On the other hand, soil elements are discretised using eight node, nine node and twelve node continuum elements. Further, three degrees of freedom at each node, i.e., displacement in three directions in $\mathrm{X}, \mathrm{Y}$ and $\mathrm{Z}$ of these different elements are employed in the present investigation. To ensure proper mechanics of stress transfer between soil and pile under lateral load, 16 node iso-parametric surface elements is introduced at the interface. The normal and tangential stiffness of these elements are assumed in such a way that shearing at the soil and pile interface is allowed but gapping will be restricted. 
Since a 3-D geometric model is used to represent the soil-pile system, selection of the correct finite element to represent the medium is one of the very important aspects in finite element analysis. In the soil-pile system, two materials, viz. soil and reinforced concrete are to be modeled. The either material show different behaviors when subjected to loading. The failure of the soil is dominated by its shear characteristics, whereas the flexure dominated failure is shown by the reinforced concrete. Therefore, pile and pile cap along with the superstructure elements are modeled using twenty node continuum elements. This element has quadratic shape function which is well suited to model the medium with bending dominated deformation. Eight node continuum elements are used to model the soil which has linear shape functions. These elements are suitable for the medium whose deformations are dominated by shear strength. To maintain the continuity of displacements between these two types of elements in the discretised soil-pile domain, two more elements were formulated, viz. twelve node and nine node solid elements. The shape functions of these two elements were formulated by using degrading technique as employed by Krishnamoorthy [45]. The shape functions are derived for these elements by degrading the twenty node solid elements. Twelve node elements are used at the junction where eight node and twenty node element meets. Further, nine node elements are used where twelve node element and twenty node element meets perpendicularly.

\section{Problem Description}

A 3-D single storeyed building frame resting on pile foundation, as shown in the 1 , is considered for the study. The frame, $3 \mathrm{~m}$ high is $10 \mathrm{~m} \times 10 \mathrm{~m}$ in plan with each bay being, $5 \mathrm{~m} \times 5 \mathrm{~m}$. The slab, $200 \mathrm{~mm}$ thick, is provided at top as well as at the floor level. Slab at top is supported over $300 \mathrm{~mm}$ wide and $400 \mathrm{~mm}$ deep beam. The beams are resting on columns of size $300 \mathrm{~mm} \times 300 \mathrm{~mm}$.

Two pile groups comprising two and three piles are considered in the present study. Further, two arrangements of piles with respect to the direction of load (series and parallel) are considered (Figure 1). All the piles in a group are circular piles, connected by $500 \mathrm{~mm}$ thick flexible pile cap. While dead load is considered according to unit weight of the materials of which the structural components of frame are made up for the purpose of the parametric study presented here, lateral load as shown in the Figure 2 are also considered. The properties of the material for pile and pile cap are given in Table 1.

Figure 3 shows the mathematical model of the building frame with the modeling idealizations mentioned in the preceding section. For group configuration in series and parallel arrangements, full 3-D geometric model is used. One subroutine is developed in the program to generate the geometrical and material properties required for finite element analysis. Figure 4(a) and Figure 4(b) shows the descritised soil-pile domain for the full 3-D

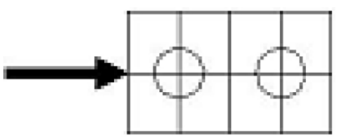

SERIES CONFIGURATION

(G2PS)

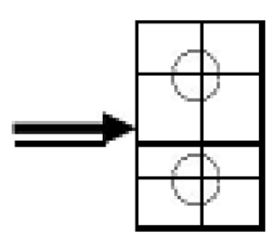

PARALLEL CONFIGURATION (G2PP)

(a)

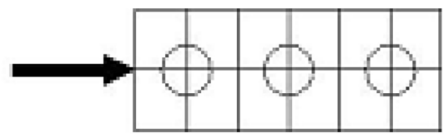

SERIES CONFIGURATION (G3PS)

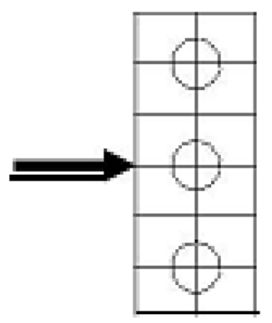

PARALLEL CONFIGURATION (G3PP)

(b)

Figure 1. Different arrangement of piles considered in the study. (a) Two-pile group; (b) Three-pile group 


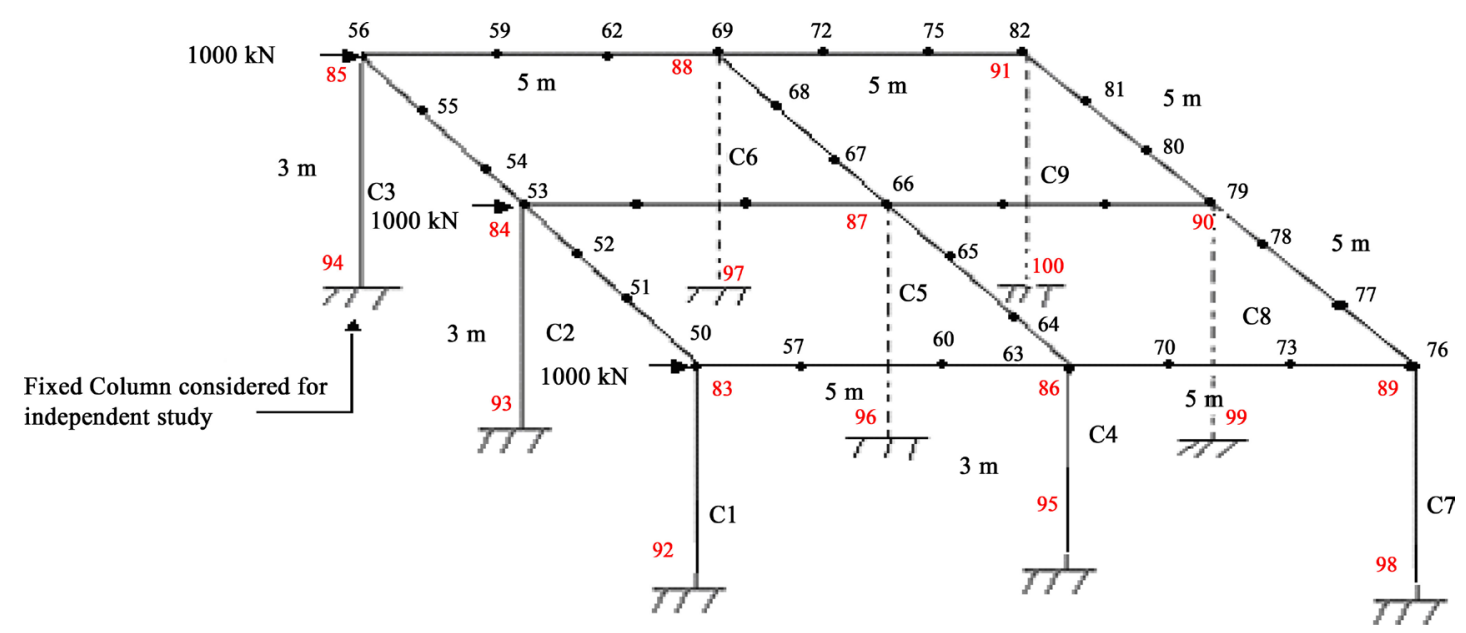

Figure 2. Typical building frame considered in the study (After Chore and Ingle [14]).

Table 1. Geometrical and material properties for the elements of the frame and foundation.

\begin{tabular}{cc}
\hline Properties & Corresponding Values \\
\hline Pile diameter $(D)$ & $300 \mathrm{~mm}$ \\
Length of pile $(L)$ & $3 \mathrm{~m}(3000 \mathrm{~mm})$ \\
Thickness of pile cap & $500 \mathrm{~mm}$ \\
Grade of concrete used for frame elements & M-20 (as per Indian Specification) \\
Characteristic compressive strength: $20 \mathrm{MPa}$
\end{tabular}

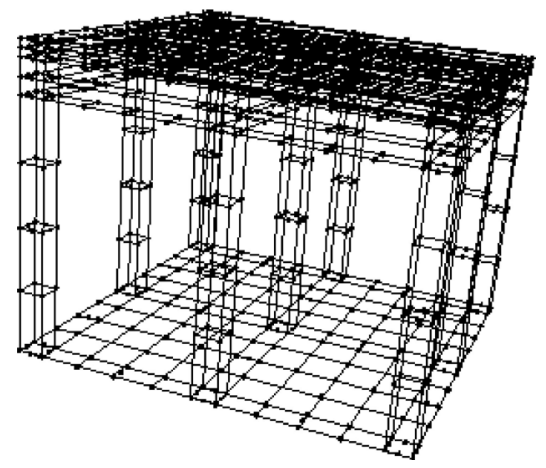

Figure 3. F.E. model of the building frame [14].

geometrical model which is used for the analysis of four configurations of pile group viz. 2PP (two piles in parallel), 2PS (two piles in series), 3PP (three piles in parallel), 3PS (three piles in series). When the load is acting along the line joining the center of pile then, it is called as series along $\mathrm{X}$ and $\mathrm{Y}$ directions, the boundary is kept at 14D ( $\mathrm{D}$ being the diameter of the pile) from the outermost pile of the pile group in respective directions. The 


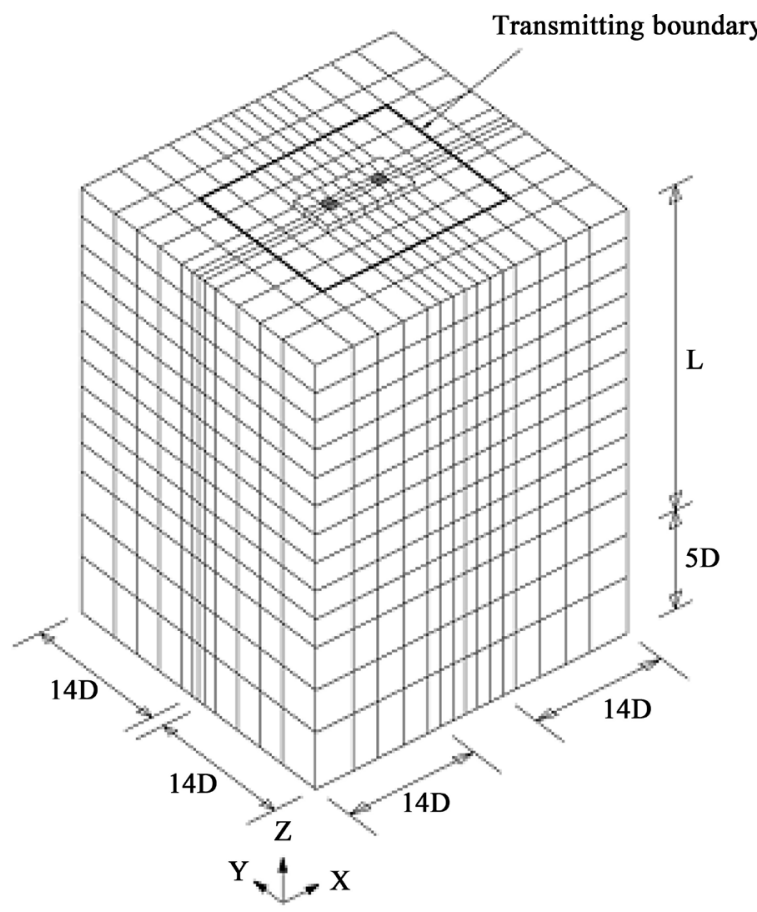

(a)

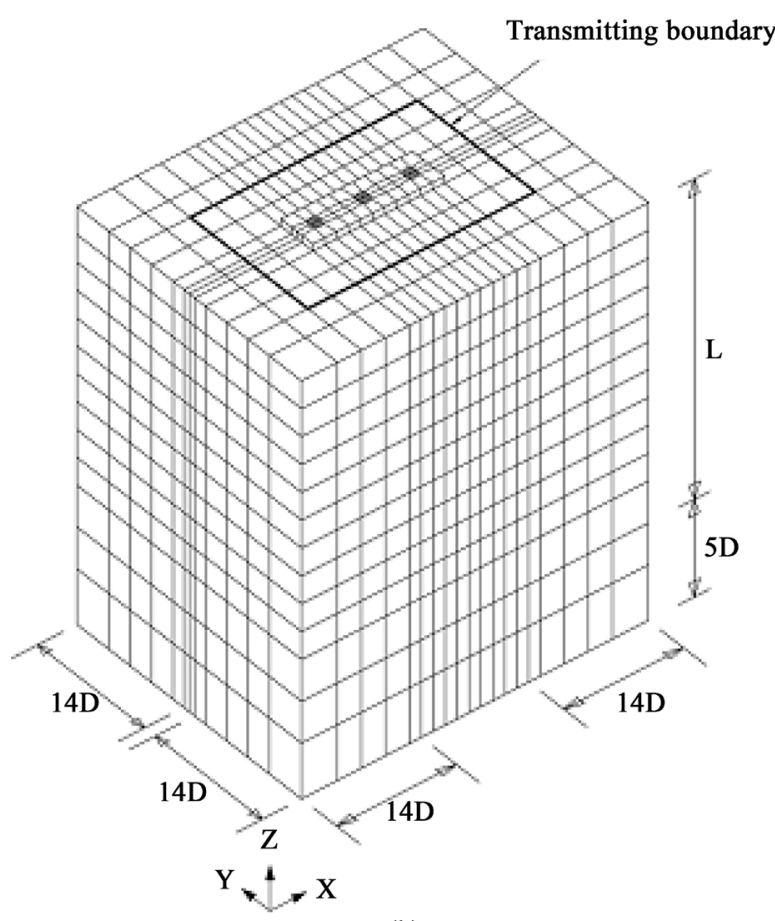

(b)

Figure 4. Typical F.E. mesh for a group of two piles and three piles. (a) Group of two piles (series and parallel); (b) Group of three piles (series and parallel).

position of the transmitting boundary is also shown by thick line as is evident from the afore-mentioned figures. However, this boundary is meant to be used in the dynamic analysis and hence, is beyond the scope of the investigations reported in this paper.

Three different spacing between the piles in a group (3D, 4D and 5D) are considered and two pile diameters such as $300 \mathrm{~mm}$ and $400 \mathrm{~mm}$ are considered.

\section{Results and Discussion}

For analyzing the pile foundation separately a software program Pile_Routine was used. The analysis of the pile foundation is carried out for the lateral or vertical force $\left(F_{H}\right.$ or $\left.F_{V}\right)$ of magnitude of $1000 \mathrm{kN}$ applied on pile cap. The equivalent stiffness, $k_{h}$ and $k_{v}$, are calculated and are further used in the interaction analysis of the frames structure. For the interaction analysis, a software programme Build_Frame is developed. The software programs are developed using FORTRAN 90.

After assessing the accuracy of the programme in the context of simple problems of structural engineering and soil-structural engineering and further, implementing it on the published work, the said program is used in the present study. In the parametric study conducted for the specific frame presented here, the response of the superstructure considered for the comparison include the horizontal displacement of the frame at top of the frame, for both fixed base and soil-structure interaction (SSI) cases.

The displacements of frame evaluated in respect of various arrangement of piles group is shown in Table 2. From the results of parametric study conducted on a specific building frame with pile foundation of different configurations as mentioned in the preceding section, it is observed that top displacement is very less (38.18 mm) when the column bases are assumed to be fixed and increases when the effect of soil-structure interaction is taken into consideration. Incorporation of the aspect of soil-structure interaction is found to increase the top displacement in the range of $97 \%$ - 230\% when compared with the displacement obtained in view of the fixed base condition.

The general trend observed for all the configurations considered in the investigation in respect of all pile diameters is that horizontal displacement is more when the spacing between two piles is kept 3D and thereafter, decreases for higher spacing, i.e., 3D, 4D and 5D, in all the configurations considered in this study. This trend of 
Table 2. Top displacement and percentage increase in top displacement with SSI.

\begin{tabular}{|c|c|c|c|c|c|c|}
\hline \multicolumn{7}{|c|}{ Top displacement obtained assuming column bases to be fixed: $38.18 \mathrm{~mm}$} \\
\hline \multicolumn{4}{|c|}{ Top Displacement (mm) } & \multicolumn{3}{|c|}{ Percentage Increase } \\
\hline Diameter & $3 \mathrm{D}$ & $4 \mathrm{D}$ & $5 \mathrm{D}$ & $3 \mathrm{D}$ & $4 \mathrm{D}$ & $5 \mathrm{D}$ \\
\hline \multicolumn{7}{|c|}{ Group of two piles (series arrangement) [G2PS] } \\
\hline 300 mm & 121 & 114 & 106 & 217 & 199 & 178 \\
\hline $400 \mathrm{~mm}$ & 102 & 95.90 & 91.10 & 167 & 151 & 139 \\
\hline \multicolumn{7}{|c|}{ Group of two piles (parallel arrangement) [G2PP] } \\
\hline 300 mm & 126 & 121 & 116 & 230 & 217 & 204 \\
\hline $400 \mathrm{~mm}$ & 106 & 102 & 96.90 & 178 & 167 & 160 \\
\hline \multicolumn{7}{|c|}{ Group of three piles (series arrangement) [G3PS] } \\
\hline 300 mm & 94.80 & 90.70 & 85.40 & 148 & 138 & 124 \\
\hline $400 \mathrm{~mm}$ & 85.10 & 75.90 & 75.30 & 123 & 99 & 97 \\
\hline \multicolumn{7}{|c|}{ Group of three piles (parallel arrangement) [G3PP] } \\
\hline $300 \mathrm{~mm}$ & 105 & 100 & 96.20 & 175 & 162 & 152 \\
\hline $400 \mathrm{~mm}$ & 91.90 & 87 & 83.90 & 139 & 128 & 120 \\
\hline
\end{tabular}

reduction in displacement with increase in spacing could be attributed to the overlapping of stressed zones of individual piles at closer spacing. When the piles are closer, combined action of pile and that of pile cap is more rigid; and moreover, in three dimensional formulation, it reflects block action. Owing to this, displacement is observed more for spacing of 3D; and thereafter, it goes on decreasing.

Effect of the configuration of the pile group on response of the superstructure is quite significant. It is obvious from the results that for the parallel arrangement, displacements obtained are on higher side as compared to the series arrangement. This holds good for all pile diameters considered in the study and even for either group, i.e., groups comprising two and three piles. The series arrangement offers stiffer behavior than parallel arrangement. This is because the combined structural stiffness of pile and pile cap in parallel arrangement is small as compared to that in series arrangement. This can be attributed to the larger area available for the development of passive resistance.

It is seen further that with increase in a diameter of pile, the displacement at top of the frame decreases for any spacing within the configuration of the pile group under consideration. This is because with increase in diameter, stiffness of the pile group gets increased. It is also observed that with increase in number of piles in a group of the identical configuration, displacement at the top of the frame decreases. More number of piles increases the stiffness of the pile group which further results in the reduction in displacement.

\section{Conclusions}

The broad conclusions emerging from the interaction analysis of the typical building frame are given below.

- The effect of soil-structure interaction on top displacement of the frame is quite significant. Displacement is less for the conventional analysis, i.e., fixed base condition and increases in the range of $97 \%-230 \%$ when the effect of SSI is taken into consideration.

- The displacement at top of frame decreases with increase in pile spacing.

- The effect of configuration of the pile group is significant on the displacement. The series arrangement offers stiffer behavior than parallel arrangement.

- The diameter and number of piles in a group under identical arrangement are important. Increase in these two parameters enhances the stiffness of the pile group as a result of which the displacement decreases.

\section{References}

[1] Chameski, C. (1956) Structural Rigidity in Calculating Settlements. Soil Mechanics and Foundation Engineering, 82, $1-9$.

[2] Morris, D. (1966) Interaction of Continuous Frames and Soil Media. Journal of Structural Engineering, 5, 13-43. 
[3] Lee, I.K. and Brown, P.T. (1972) Structures and Foundation Interaction Analysis. Journal of Structural Engineering, 11, 2413-2431.

[4] King, G.J.W. and Chandrasekaran, V.S. (1974) Interactive Analysis of a Rafted Multi-Storeyed Space Frame Resting on an Inhomogeneous Clay Stratum. Proc. Int. Conf. Finite Element Methods, Australia, 493-509.

[5] Buragohain, D.N., Raghavan, N. and Chandrasekaran, V.S. (1977) Interaction of Frames with Pile Foundation. Proc. Int. Symp. Soil-Structure Interaction, Roorkee, 109-115.

[6] Sriniwasraghavan, R. and Sankaran, K.S. (1981) Settlement Analysis for Combined Effect of Superstructure-FootingsSoil System. Journal of the Institution of Engineers (India), 6, 194-198.

[7] Subbarao, K.S., ShradaBai, H. and Raghunatham, B.V. (1985) Interaction Analysis of Frames with Beam Footing. Proc. Indian Geotech. Conf., Roorkee, 389-395.

[8] Deshmukh, A.M. and Karmarkar, S.R. (1991) Interaction of Plane Frames with Soil. Proc. Indian Geotechnical Conf., Surat, 323-326.

[9] Viladkar, M.N., Godbole, P.N. and Noorzaei, J. (1991) Soil-Structure Interaction in Plane Frames Using Coupled Finite-Infinite Elements. Computers and Structures, 39, 535-546. http://dx.doi.org/10.1016/0045-7949(91)90062-Q

[10] Noorzaei, J., Viladkar, M.N. and Godbole, P.N. (1991) Soil-Structure Interaction of Space Frame-Raft-Soil System: Parametric Study. Computers and Structures, 40, 235-1241. http://dx.doi.org/10.1016/0045-7949(91)90394-2

[11] Dasgupta, S., Dutta. S.C. and Bhattacharya, G. (1998) Effect of Soil-Structure Interaction on Building Frames on Isolated Footings. Journal of Structural Engineering, 26, 129-134.

[12] Mandal, A., Moitra, D. and Dutta, S.C. (1999) Soil-Structure Interaction on Building Frame: A Small Scale Model Study. International Journal of Structure, Roorkee (India), 18, 92-107.

[13] Chore, H.S. and Ingle, R.K. (2008) Interaction Analysis of Building Frame Supported on Pile Group. Indian Geotechnical Journal, 38, 483-501.

[14] Chore, H.S. and Ingle, R.K. (2008) Interactive Analysis of Building Frame Supported on Pile Group Using a Simplified F.E. Model. Journal of Structural Engineering, 34, 460-464.

[15] Chore, H.S., Ingle, R.K. and Sawant, V.A. (2009) Building Frame-Pile Foundation-Soil Interactive Analysis. Interaction and Multiscale Mechanics: An International Journal, 2, 397-412. http://dx.doi.org/10.12989/imm.2009.2.4.397

[16] Chore, H.S., Ingle, R.K. and Sawant, V.A. (2010) Building Frame-Pile Foundation-Soil Interaction Analysis: A Parametric Study. Interaction and Multiscale Mechanics, 3, 55-80. http://dx.doi.org/10.12989/imm.2010.3.1.055

[17] Sawant, V.A. and Chore, H.S. (2010) Building Frame-Pile Foundation-Soil Interactive Analysis Using 3-D FEM. Journal of Structural Engineering (JoSE), 36, 318-325.

[18] Reddy, R.C. and Rao, G.T.D. (2011) Experimental Study of a Modelled Building Frame Supported by a Pile Group Embedded in Cohesionless Soils. Interaction and Multiscale Mechanics, 4, 321-336. http://dx.doi.org/10.12989/imm.2011.4.4.321

[19] Agrawal, R. and Hora, M.S. (2009) Coupled Finite-Infinite Elements Modeling of Building Frame-Soil Interaction System. Journal of Engineering and Applied Sciences, 4, 47-54.

[20] Agrawal, R. and Hora, M.S. (2010) Effect of Differential Settlements on Non-Linear Interaction Behaviour of Plane Frame-Soil System. Journal of Engineering and Applied Sciences, 5, 75-87.

[21] Thangaraj, D.D. and Illampurthy, K. (2010) Parametric Study on the Performance of Raft Foundation with Interaction of Frame. Electronic Journal of Geotechnical Engineering, 15, 861-878.

[22] Dalili, M., Alkarami, A., Noorzaei, J., Paknahad, M., Jaafar, M.S. and Huat, B. (2011) Numerical Simulation of SoilStructure Interaction in Framed and Shear-Wall Structures. Interaction and Multiscale Mechanics, 4, 17-34. http://dx.doi.org/10.12989/imm.2011.4.1.017

[23] Rajsekar Swamy, H.M., Krishnammorthy, A., Prabhakara, D.L. and Bhavikatti, S.S. (2011) Evaluation of the Influence of Interface Elements for Structure-Isolated Footing-Soil Interaction Analysis. Interaction and Multiscale Mechanics, 4, 65-83. http://dx.doi.org/10.12989/imm.2011.4.1.065

[24] Thangaraj, D.D. and Illampurthy, K. (2012) Numerical Analysis of Soil-Mat Foundation of Space Frame System. Interaction and Multiscale Mechanics, 5, 267-284. http://dx.doi.org/10.12989/imm.2012.5.3.267

[25] Polous, H.G. (1968) Analysis of Settlement of Pile Groups. Geotechnique, 18, 449-471. http://dx.doi.org/10.1680/geot.1968.18.4.449

[26] Butterfield, R. and Banerjee, P.K. (1971) The Problem of Pile Group and Pile Cap Interaction. Geotechnique, 21, 135-142. http://dx.doi.org/10.1680/geot.1971.21.2.135

[27] Coyle, H.M. and Reese, L.C. (1966) Load Transfer for Axially Loaded Pile in Clay. Journal of the Soil Mechanics and Foundations Division, 92, 1-26. 
[28] Hazarika, P.J. and Ramasamy, G. (2000) Response of Piles under Vertical Loading. Indian Geotechnical Journal, 30, 73-91.

[29] Basarkar, S.S. and Dewaikar, D.M. (2005) Development of Load Transfer Model for Socketted Tubular Piles. Proceedings of International Geotechnical Conference on Soil-Structure Interaction-Calculation Methods and Engineering Practice, St. Petersburg, 26-28 May 2005, 117-122.

[30] Spiller, W.R. and Stoll, R.D. (1964) Lateral Response of Piles. Journal of the Soil Mechanics and Foundation Engineering, 90, 1-9.

[31] Poulos, H.G. (1971) Behaviour of Laterally Loaded Piles: II. Group of Piles. Journal of the Soil Mechanics and Foundation Engineering, 97, 733-751.

[32] Banerjee, P.K. and Davis, T.G. (1978) The Behaviour of Axially and Laterally Loaded Single Piles Embedded in Non-Homogeneous Soils. Geotechnique, 28, 309-326. http://dx.doi.org/10.1680/geot.1978.28.3.309

[33] Matlock, H. and Reese, L.C. (1961) Foundation Analysis of Offshore Pile Supported Structures. Proceedings of the 5th International Conference on Soil Mechanics and Foundation Engineering, Paris, 17-22 July 1961, 91-97.

[34] Matlock, H. (1970) Correlations for Design of Laterally Loaded Piles in Soft Clay. Proceedings of the 2nd Offshore Technology Conference, Houston, 22-24 April 1970, 577-594. http://dx.doi.org/10.4043/1204-ms

[35] Georgiadis, M., Anagnostopoulos, C. and Saflekou, S. (1992) Cyclic Lateral Loading of Piles in Soft Clay. Geotechnical Engineering, 23, 47-60.

[36] Dewaikar, D.M. and Patil, P.A. (2006) Analysis of a Laterally Loaded Pile in Cohesion-Less Soil under Static and Cyclic Loading. Indian Geotechnical Journal, 36, 181.

[37] Desai, C.S. and Abel, J.F. (1974) Introduction to Finite Element Method. CBS Publishers, New Delhi.

[38] Desai, C.S. and Appel, G.C. (1976) 3-D Analysis of Laterally Loaded Structures. Proceedings of the 2nd International Conference on Numerical Methods in Geomechanics, Blacksburg, 405-418.

[39] Desai, C.S., Kuppusamy, T. and Allameddine, A.R. (1981) Pile Cap-Pile Group-Soil Interaction. Journal of Structural Engineering, 107, 817-834.

[40] Ng, C.W.W. and Zhang, L.M. (2001) Three Dimensional Analysis of Performance of Laterally Loaded Sleeved Piles in Sloping Ground. Journal of Geotechnical and Geoenvironmental Engineering, 127, 499-509. http://dx.doi.org/10.1061/(ASCE)1090-0241(2001)127:6(499)

[41] Krishnamoorthy, C.S., Rao, N.B.S. and Rao, N. (2005) Analysis of Group of Piles Subjected to Lateral Loads. Indian Geotechnical Journal, 35, 154-175.

[42] Chore, H.S., Ingle, R.K. and Sawant, V.A. (2010) Parametric Study of Pile Groups Subjected to Lateral Load. Structural Engineering and Mechanics, 26, 243-246. http://dx.doi.org/10.12989/sem.2010.36.2.243

[43] Chore, H.S., Ingle, R.K. and Sawant, V.A. (2012) Parametric Study of Laterally Loaded Pile Groups Using Simplified F.E. Models. Coupled Systems Mechanics, 1, 1-7. http://dx.doi.org/10.12989/csm.2012.1.1.001

[44] Chore, H.S., Ingle, R.K. and Sawant, V.A. (2012) Non-Linear Analysis of Pile Groups Subjected to Lateral Loads Using $p$-y Curve. Interaction and Multiscale Mechanics, 5, 57-73. http://dx.doi.org/10.12989/imm.2012.5.1.057

[45] Krishnamoorthy, C.S. (2010) Finite Element Analysis: Theory and Programming. 2nd Edition, Tata McGraw-Hill Publications, New Delhi. 